\title{
Judicial Understandings of Aboriginality and Language Use in Criminal Cases ${ }^{1}$
}

\section{Introduction}

Ian Keen is highly respected for his seminal research on complex relationships between social group, kinship, religion, economy, knowledge and territory, particularly in remote Australia. Much of this work has been applied in land rights and native title claims, in which contests over the social identities of claimants are often central. As highlighted in the Yorta Yorta native title claim in Victoria, judicial officers have considerable power to accept or reject who people say they are, with far-reaching implications. But Ian's contributions to the study and understanding of Aboriginal identity have extended much further than his research in remote Australia and its connections to land. His early interest in diverse aspects of identity led to his 1988 edited book Being Black: Aboriginal Cultures in 'Settled' Australia, which was a groundbreaking work in the understanding of Aboriginal identity, interactions, and culture in nonremote Australia. As he wrote in the introduction, there had been a tendency

\footnotetext{
1 I am grateful to Ian Keen whose patient, supportive and insightful supervision of my $\mathrm{PhD}$ in the early 1980s played a important role in launching my ongoing investigations into Aboriginal ways of using English. In expanding my understanding of some of the issues canvassed in this chapter, I owe gratitude to participants in the 2012 Uluru Criminal Lawyers conference, especially Judge Dean Mildren, retired judge John Nicholson, and then Senior Public Defender Dina Yehia (now District Court Judge). Thanks also to Jeff Siegel and Peter Toner and two anonymous reviewers for helpful comments on the draft. All remaining errors are my responsibility. I do not intend to imply that any of these people agree with my analysis.
} 
by many - scholars and others - to regard Aboriginal people who did not live in remote Australia from a deficit perspective. They were seen as people who had 'lost their culture', and were somehow less Aboriginal (if indeed they were Aboriginal at all) than those whose remote location had resulted in less disruption to their lives. Keen's book was the first to bring together and extend ethnographic studies which recognised and exemplified contemporary Aboriginal identities and cultures in 'settled' Australia.

While Keen's use of Rowley's (1971) term 'settled' Australia worked well in 1988, more than two decades later this term seems less appropriate, given the possible present-day connotations of 'at rest' or no longer contested. This chapter deals with identity issues of Aboriginal people who do not live in remote Australia and who speak varieties of English as their main language, often their only language. Where necessary, I will refer to Aboriginal people in 'southern Australia', while recognising that this label is less than ideal. To Keen's (1988: 3) observation of such people forming 'part of a distinct, though heterogenous and loosely bounded ethnic category', we can add the twenty-first century understanding that ethnic identities are typically hybrid, dynamic and multiple.

This chapter discusses how judicial decision-makers understand Aboriginal identity, specifically in the criminal justice system. As in land claim and native title processes, the criminal justice process centres on fundamental questions about whose story can be believed, or which parts of which stories can be believed, and in these questions Aboriginal identity and culture can be important considerations. Length limitations will prevent me from considering further parallels between these different legal processes. And a longer work would situate this discussion of Aboriginality in southern Australia in the current contests and misunderstandings among Australians from a wide range of backgrounds, which is frequently seen in public discourse, (such as then Opposition Leader Tony Abbott's November 2012 comment that Western Australia's first Aboriginal member of parliament, Ken Wyatt, is 'not a man of culture' (Aikman 2012)).

Aboriginality has been a prominent focus of the criminal justice system in the past 25 years, particularly in terms of one of the most fundamental human rights, namely that 'all people are equal before the law' (Article 7, Universal Declaration of Human Rights). This right entails being 'entitled without any discrimination to the equal protection of the law' (International Covenant on Civil and Political Rights 1966). Judicial officers (judges and magistrates) take an oath to administer the law 'without fear or favour, affection or ill-will'. Guidance for Australian judicial officers about their day-to-day practice in court is clear about equal treatment being different from the same treatment, as seen in the opening section of the NSW Equality before the Law Bench Book (Judicial Commission of NSW 2009: 1103): 
Equality before the law is sometimes misunderstood. It does not necessarily mean 'same treatment'. As McHugh J succinctly explained: 'discrimination can arise just as readily from an act which treats as equals those who are different as it can from an act which treats differently persons whose circumstances are not materially different'.2

The principle explained by Justice McHugh is pertinent all over Australia on a daily basis in the ways that the criminal justice system deals with Aboriginal people. This chapter considers one factor which can be central to the participation of many Aboriginal people in the criminal justice process, namely ways in which judicial officers understand Aboriginal identities, practice and culture.

The discussion will start with a 1987 case that highlights an approach to Aboriginal identity which centres on biological and phenotypical assessment, and which exemplifies important real-world consequences of the denial of Aboriginality which Keen (1988) set out to counter. I then briefly sketch some important developments in judicial understandings. I outline the main judicial context in which Aboriginality has been considered, namely in sentencing convicted offenders. Sentencing contexts are not the main focus of this chapter, however, which instead turns to matters concerning communication between witnesses (including defendants) and officers within the legal process, including police officers, lawyers, magistrates and judges. The discussion of selected cases between 1993 and 2006, together with consideration of related judiciary-led developments underline my argument (e.g. 1992, 1993, 1996a, 2008, 2013) for the need for the legal system to recognise Aboriginal ways of using English. In this discussion we will see evidence of the difficult task that judicial officers can be faced with in deciding whether and how Aboriginal identity is relevant in individual cases.

The chapter will argue that judicial officers need to distinguish between sentencing contexts on one hand, and contexts of communication in legal settings on the other, in their consideration of Aboriginality. The role of alcohol in lives characterised by often extreme disadvantage, including illiteracy and other 'grave social difficulties' (see 'Grave Social Difficulties') is often central to the judicial consideration of Aboriginality in sentencing. But there is no inherent connection between these negative (and distressing) living conditions experienced by many Aboriginal people and their language variety - in southern Australia, their Aboriginal use of English. Yet in cases in which communication with Aboriginal English speakers is central (for example, with prosecution witnesses in a murder case, see 'A Problem-Centred Approach to Aboriginal Ways of Using English'), a focus on problems experienced by Aboriginal people can sometimes connect to a deficit view of Aboriginal identity and social

2 In Waters v Public Transport Corporation (1991: 402). See also Queensland Supreme Court (2005: 14). 
practice, while at the same time preventing the court from engaging in effective intercultural communication. Thus, this chapter highlights how an ongoing deficit approach to Aboriginal identity in southern Australia, addressed by Keen and others in his 1988 book, can still, at times, play a role in the criminal justice system, with disturbing social consequences.

The discussion in this chapter will draw primarily on judgments, that is written decisions of one or more judges in a case, which outline the facts, discuss the evidence and refer to legislation and case law on which the judicial decision is based (Family Court of Australia). In discussing judgments, this chapter will use the legal convention of referring to judges with the form 'Last Name $J$ ' and to judges who are President of the Appeal Court as 'Last Name $\mathrm{P}^{\prime}$. It is not my intention to comment on legal reasoning or to analyse the complexity of individual cases, nor do I have the expertise required.

\section{‘... Of Only Partly Aboriginal Extraction’}

The year before Keen's (1988) book on Aboriginal identity and culture in 'settled' Australia was published, an appeal judgment in a Queensland case ( $R \cup$ Condren 1987) highlighted the conception of Aboriginality through the discourse of race, as well as the language ideology that language acquisition and use is dependent on biology.

Kelvin Condren, who had grown up in Townsville, was found guilty of the brutal murder of a woman in Mount Isa in 1983, on the basis of a signed confession allegedly given in answers to questions he was asked in a police interview. One of the grounds for Condren's 1987 appeal was related to linguistic evidence which supported his claim that the police transcript of their interview with him had not been typed verbatim, as they had claimed. (Thus, this case revolved around Condren's allegation that his 'confession' had been fabricated.) This linguistic evidence compared the grammatical structures and ways of communicating (or pragmatic patterns) in answers in the so-called confession to those in other interviews Condren had had in legal contexts, and to general research about Aboriginal English patterns (see Eades 1993, 2013: Chapter 8). Although the linguistic evidence was heard in full in the appeal hearing, it was ruled as legally inadmissible.

Several reasons were given for the inadmissibility ruling (see Eades 1997), including the judges' refusal to accept that there could be a specialised field of knowledge that could analyse the English spoken by Aboriginal people. The reason pertinent to the discussion in this chapter can be characterised as 
the judges' finding that Condren was not 'Aboriginal enough' (my term, see also Flynn 2005) for evidence about Aboriginal use of English to be relevant, if indeed they had accepted that there could have been such a kind of expertise.

This finding drew on the discourse of skin colour and fractions of racial descent, which had predominated for decades in colonial and neocolonial discourse. While no longer used in government censuses after the 1967 referendum (Rowse 2012: 9), and also discredited in the social sciences by 1987, these crude biological and phenotypical assessments of Aboriginal people in the 1987 Condren judgment mirrored much public discourse at that time. Ambrose $\mathrm{J}(R v$ Condren 1987: 276) drew a general distinction between 'full-blooded tribal Aboriginals' and 'part-blooded urban Aboriginals'. Referring specifically to Condren, he mentioned the 'absence of any clear evidence as to the genealogy of the appellant and ... the fact that neither of his parents were full-blooded Aboriginals' ( $p$. 297). Ambrose J also observed Condren's mother giving evidence at the appeal and commented in his judgment: 'Upon my assessment of that lady's appearance and manner, I certainly formed the impression that she was of only partly Aboriginal extraction and indeed that part was not predominant' (p. 275). ${ }^{3}$

Condren's appeal judgment illustrates a taken-for-granted perspective that biological characteristics, such as skin colour and fraction of racial descent, can account for language acquisition, exposing acceptance of a general approach which has been disparagingly labelled 'the pathology of ethnicity'. It highlighted the way in which (possibly most) members of the judiciary at that time were both removed from and ignorant of Aboriginal social life and culture. ${ }^{4}$

\section{Contexts of Developing Judicial Understandings}

Within just a few years of Condren's appeal, the Royal Commission into Aboriginal Deaths in Custody exposed and explored the complex relationships between the criminal justice system and Aboriginal people, in its investigation into their extraordinary over-representation in the country's police cells and prisons. The Royal Commission found that 'the most significant contributing factor' to this over-representation was 'the disadvantaged and unequal position in which people find themselves in the society-socially, economically, and culturally' (Johnston 1991: 15). The extensive report on the ways in which this

\footnotetext{
3 It appears that many, if not most, of the decisions which consider whether a person is 'Aboriginal enough' are from southern Australian cases. In contrast, Condren had lived in and near the north Queensland cities of Townsville and Mount Isa most of his life (on 'the rolling side of the frontier', in Langton's (1981: 17) terms) and also in an Aboriginal community in Central Australia.

4 In 1990, the Queensland appeal court found that Condren had been wrongfully convicted, and his seven years in prison came to an end.
} 
'disadvantaged and unequal position' brings Aboriginal people 'into conflict with the criminal justice system' marked a watershed in terms of making the legal system realise that Aboriginal people and societies could no longer be ignored. The Royal Commission's extensive investigations and findings have impacted the criminal justice system, and the judiciary specifically, in numerous and diverse ways. ${ }^{5}$ Of its 339 recommendations, one specifically addressed judicial awareness, dealing with the need for judicial officers (among others) to have training about 'contemporary Aboriginal society, customs and traditions', as well as participating 'in discussion with members of the Aboriginal community in an informal way in order to improve cross-cultural understanding' (Johnston 1991: 53).

In response, several state courts have established court committees or programs to promote understanding of Aboriginal people and cultures, such as the NSW Judicial Commission's Ngara Yura Program (since 1992). In addition to conventional judicial training approaches, such as workshops, conferences and publications, this program runs a popular series of community visits. Judicial officers make a field trip to a selected Aboriginal community, where they have the opportunity to talk to local people, 'to enhance their understanding and appreciation of the history and culture' and 'to exchange information and ideas on issues of mutual concern, including cultural and language differences' (Judicial Commission of New South Wales n.d.).

At the national level, professional development programs for judicial officers are central to the work of the National Judicial College of Australia, established in 2002. With programs developed and delivered by committees of judges or magistrates, and drawing on other expertise as required, the college deals with a vast range of topics impacting judicial work. Many of these programs incorporate issues about understanding Aboriginal communities and witnesses (for example, in programs on Judging in Remote Localities (2008), Solution Focussed Judging (2011) and Witness Assessment (2012, 2014)).

Other significant developments in the context of judicial understandings about Aboriginal people and cultures relate to the people being appointed to judicial positions. There is a very small but growing number of Aboriginal magistrates, including Pat O'Shane (NSW, 1986-2013), Jacqui Payne (Queensland, since 1999) and Rose Falla (Victoria, appointed 2013). There has only been one Aboriginal judge, the late Bob Bellear, who was a NSW District Court judge from 1996-2004. However, there are now judges at the highest levels who had earlier

\footnotetext{
5 However, this over-representation has not been reduced. Statistics for 2013 show that Indigenous people (of whom the majority are Aboriginal) are imprisoned at 13 times the rate of the general population (age-adjusted figures), while Indigenous young people are in juvenile detention at about 24 times the rate of the general population (SCRGSP 2014).
} 
worked as young lawyers in the newly established Aboriginal Legal Services in the 1970s. Over decades, these Aboriginal organisations, which have provided unparalleled service to Aboriginal people, have also trained many lawyers in understanding Aboriginal social and cultural life, and many of these lawyers have gone on to work as judicial officers. One such example is the current Chief Justice of the High Court of Australia, Robert French (Skyring 2011: 13). Other contemporary judges have had other close involvements with Aboriginal people and issues over many decades since their student days or early work as lawyers. For example, the Chief Justice of the NSW Supreme Court from 1988-2011, Jim Spigelman, was one of the 34 university students who made the 1965 Freedom Ride to expose and protest about segregation and racism against Aboriginal people in NSW country towns (Curthoys 2002).

\section{'Grave Social Difficulties'}

The judiciary's expanded awareness of the need to understand Aboriginal social life has been particularly focused, in the criminal justice system, on decisions about sentencing. This is perhaps their most significant and difficult job in most cases where an offender is convicted. In making the decision about sentencing, judicial officers usually have discretion in exercising their responsibility to balance the main punishment aims of retribution, deterrence and rehabilitation. ${ }^{6}$ The sentencing decision involves not only balancing these punishment aims, but also taking into account a wide range of relevant 'material facts' concerning the nature of the offence, the nature of the offender, and the effect of the offence and the penalty (Findlay, Odgers and Yeo 2005: Chapter 8). One of the cases which established that an offender's Aboriginality may often be a relevant consideration was the 1982 Neal High Court case. Brennan J held that material facts to be taken into account in sentencing include 'those facts which exist only by reason of the offender's membership of an ethnic or other group' (Neal $v R$ 1982: 326).

Ten years later, with the benefit of the final report and recommendations of the Royal Commission into Aboriginal Deaths in Custody, as well as judgments in a number of cases, including Neal, Wood J set out 12 specific principles in $R v$ Fernando (p. 61). The principles from this 1992 NSW Supreme Court trial have become one of the most important and detailed precedents in the sentencing of Aboriginal people throughout the country. At the centre of these sentencing principles is recognition of the problems of alcohol abuse and violence which to a very significant degree go hand in hand with Aboriginal

6 However, judicial officers are sometimes provided with little sentencing discretion, namely in jurisdictions where governments have legislated mandatory sentences for some offences. 
communities' and that the 'cure [of these problems] requires more subtle remedies than the criminal law can provide by way of imprisonment' (p. 61). A key element includes the need for

the realistic recognition by the court of the endemic presence of alcohol within Aboriginal communities, and the grave social difficulties faced by those communities where poor self-image, absence of education and work opportunity and other demoralising factors have placed heavy stresses on them, reinforcing their resort to alcohol and compounding its worst effects. ( $R v$ Fernando 1992: 62-3)

But concerns are being expressed about the ways in which the Fernando principles are being 'narrow[ed]' in application (Flynn 2005), or 'retreat[ed] from' (Edney 2006; see also Anthony 2010: 3; Nicholson 2012 and Yehia 2012). Edney argues that in a number of NSW appeal court judgments the application of these principles has been restricted because of judicial officers 'fundamentally misapprehending the nature of [Aboriginal] identity in a post-colonial society' (p. 17). Examples of this 'misapprehended' approach to Aboriginal identity are cited from judgments which find that the Fernando principles are not relevant because of such factors as the defendant having an urban background ( $R v$ Newman, $R v$ Simpson 2004), or having a 'part-aboriginal' grandfather ( $R v$ Ceissman 2001) or having 'had many dealings with the police, and not [being] intimidated by the idea of being questioned by them' ( $R v$ Helmhout 2001: 259). The Aboriginal identity of many people who have been described in these ways has been thus legally 'erased' or 'extinguished', in Edney's (2006) terms. ${ }^{7}$ Yet, such factors as fractional descent, place of residence and experience with the police manifestly do not enable many Aboriginal people to escape the 'grave social difficulties' enunciated by Wood. An important 2013 High Court case about the sentencing of a New South Wales Aboriginal man (Bugmy $v R$ 2013), found that 'Aboriginal Australians who live in an urban environment do not lose their Aboriginal identity and they, too, may be subject to the grave social difficulties discussed in Fernando' $(\$ 41){ }^{8}$

The fact that the Fernando principles are focused on Aboriginal alcohol abuse and violence, and linked to 'poor self-image, absence of education and work opportunity and other demoralising factors' in Aboriginal communities, was doubtless central to Fernando's case. And these negative social issues, and others such as foetal alcohol syndrome, are also relevant to many other

\footnotetext{
7 This approach to Aboriginal identity and resulting legal erasure highlights the need for scholarly writing in the social sciences (such as Keen 1988) to be accessed in law school training, and more widely made available for judicial officers and other legal professionals.

8 In this case, the High Court rejected the decision of the NSW Court of Criminal Appeal (CCA) that the social disadvantage referred to in the Fernando principles diminishes over time, especially during a person's period of incarceration. While the decision in this case is important for the issue of Aboriginal sentencing, further comment is beyond the scope of this chapter (but see Judicial Commission of New South Wales 2013, Williams 2013).
} 
Aboriginal offenders, and to central considerations in their sentencing. But, as Nicholson (2012: 4) points out, an offender's Aboriginality can also be relevant to sentencing in positive ways (for example, in cases where an offender has been making a positive contribution to the community in their role as an elder).

\section{Communication with Aboriginal Witnesses}

The Fernando principles highlight the relevance of having 'a deprived background' or being 'otherwise disadvantaged', which must often be taken into account when a judicial officer sentences an Aboriginal offender. But the life experiences focused on in these principles are seen to revolve around 'abuse of alcohol' and 'resort to violence'. While these experiences may be common to many Aboriginal people who have not learned general Australian English, they are not necessarily relevant to the way that a person speaks English, which depends on the much richer fabric of socialisation, both primary and secondary (and further), and patterns of social networking, interaction, and residence. This chapter now turns away from issues involved in the sentencing of Aboriginal offenders, to those involved in communication with Aboriginal witnesses (including defendants) and to hearing their stories in the criminal justice process. In my view Aboriginality is often relevant to the judicial officers' responsibility of ensuring that the proceedings are conducted fairly. But, it seems that this relevance of Aboriginal identity - specifically in terms of communication in interviews with police or lawyers, or during courtroom questioning - is often ignored. We will see examples of this in decisions about admissibility of evidence and directions to the jury. We turn first to two judgments in which issues concerning Aboriginal ways of using English were relevant to appeals against guilty verdicts, as with the Condren appeal discussed above. The first case discussed here deals with miscommunication between an accused person and her lawyer, and the second with communication in a police interview. Initiatives by judicial officers and state justice departments concerning trial communication with Aboriginal speakers of English are also considered. We then examine judicial decisions in two cases where Aboriginal use of English was raised in relation to courtroom communication.

Elsewhere (e.g. Eades 1992, 1994, 2008, 2013) I have written about features of Aboriginal use of English — often referred to as Aboriginal English — which are particularly relevant to communication in the legal process. ${ }^{9}$ These features can be structural (including grammatical patterns, word choice and meaning), and/ or pragmatic, that is features of language usage (including patterns of discourse

9 For discussion of the advantages and disadvantages of the terms 'Aboriginal English' and 'Aboriginal ways of speaking/using English' see Eades (2013: Chapter 1). 
and conversation). Several pragmatic features impact on Aboriginal participation in legal interviews, even when structurally the variety of English may be close to general Australian English. For example, in many western Anglo societies, silence (or a pause of more than about one second) in an interview is generally taken to mean that a speaker has nothing to say, or could be trying to invent an answer. In contrast, in much Aboriginal interaction (whether the language spoken is a variety of English or a traditional Aboriginal language) silence is used as a positive and productive part of communication. The implications of this difference in language use are extensive for the participation of Aboriginal people in legal interviews, as is the widespread use of the phenomenon known as 'gratuitous concurrence'. This term refers to the act of saying 'yes' to a question, regardless of whether the speaker agrees with the proposition being questioned, or even understands it. The strong Aboriginal tendency to use gratuitous concurrence in interviews has been documented since the mid-1800s, and makes many Aboriginal people suggestible, or highly suggestible, in police interviews and courtroom questioning, an issue we will return to below. The use of Aboriginal patterns of communication (or pragmatic language features) is not inherently connected to 'social difficulties' centred around abuse of alcohol and violence. Thus criteria such as those derived from sentencing principles will not necessarily be relevant to questions about an Aboriginal person's English usage or patterns of communication.

\section{Pre-Trial Communication Issues for Defendants}

A 1993 Queensland Appeal Court case provides a positive example of how and why Aboriginal patterns of communication can be relevant. Just six years after this court used racial and biological constructions of Aboriginal identity to reject expert sociolinguistic evidence (in Condren 1987, discussed above), the same court raised no objections to the admissibility of expert sociolinguistic evidence, this time in relation to issues involved in communication between an Aboriginal woman from southeast Queensland and her lawyers (in $R v$ Kina 1993). Kina had appealed her murder conviction on the basis that her lawyers did not find out her story and thus the jury had found her guilty in the absence of any opportunity for her to present her defence. The sociolinguistic report, which was admitted into evidence without contest, referred in part to some of the characteristics of Aboriginal ways of using English mentioned above (see Eades 1996a, 2003). The court was unanimous in finding there had been a miscarriage of justice. The judgment by Fitzgerald $P$ and Davies J accepted Kina's Aboriginality without qualification, and noted that none of her lawyers had 'received any training or instructions concerning how to communicate or deal with Aborigines' ( $R v$ Kina 1993: 21). In finding that Kina's trial had involved a miscarriage of justice, this judgment cited 'cultural, psychological and personal factors' which 'presented exceptional difficulties of communication between 
her legal representatives and the appellant'. These factors 'bore upon the adequacy of the advice and legal representation which the appellant received and effectively denied her satisfactory representation or the capacity to make informed decisions on the basis of proper advice' (pp. 35-6). (The judgment by McPherson J did not mention Kina's Aboriginality.)

Another judgment in the same court, two years later, involved more detailed consideration of southeast Queensland Aboriginal identity - this time for a teenager from Cherbourg community - in relation to issues concerning his communication with arresting police officers ( $R v$ Aubrey 1995). Sixteen-yearold Aubrey was appealing his conviction for manslaughter following the death of a man whom he had punched outside a hotel. One of the grounds of the appeal was that the confession contained in answers in the police interview should not have been admissible. This was because the interviewing officers had not followed a Queensland police directive requiring the presence of a lawyer/ legal officer when interviewing 'persons under disability' (which included 'many Aborigines', see below). The appeal was unsuccessful, and the judgments of both the two majority judges and the dissenting judge considered the issue of the appellant's Aboriginality.

In his dissenting judgment, Fitzgerald $\mathrm{P}$ referred to 'cultural problems associated with the reliability of confessional statements made by aborigines who are interrogated by white persons in positions of authority'. He held that the police commissioner's regulations, both about interviewing young people and interviewing Aboriginal people, had been ignored in Aubrey's case, and the resulting admissions that Aubrey made to police should not have been received into evidence. For Fitzgerald, the Aboriginality of this appellant from the largest Aboriginal community in Queensland was not at issue. Not only did he recognise that Aubrey was Aboriginal (as did the other two judges), but for Fitzgerald, this Aboriginality needed to be taken account of in considering the non-application of the police directive (a view in which he diverged from the decision of the other two judges). Further, Fitzgerald described as 'too narrow' the view of the trial judge that the regulations concerning police interviews of Aboriginal people were 'particularly directed to tribal people withdrawn from the European way of living', thus rejecting a consideration of Aboriginality in terms of the appellant living in a non-remote area and non-traditionally oriented lifestyle. Fitzgerald $\mathrm{P}$ found that 'by reason of his aboriginality and life experience, the appellant was "at a disadvantage in respect of the investigation, in comparison with members of the general Australia community"'. Here Fitzgerald P cited Kearney J's finding (in $R v$ Butler 1991) that the Anunga guidelines - on which the Queensland police guidelines were based-were designed to overcome 'a particular vulnerability of Aboriginals to police interrogation, and in the exercise of the right to silence'. (While Fitzgerald $\mathrm{P}$ 
did not refer specifically to gratuitous concurrence, this phenomenon is clearly one of the issues addressed in the Anunga guidelines for police interviews with Aboriginal people (see Douglas 1998).)

While the two majority judges in this appeal did not question that Aubrey was Aboriginal, they questioned whether he was an Aboriginal person under disability in terms of the police regulations. Unlike the trial judge and some of the judges in the sentencing cases referred to above, they did not draw on the fact that the appellant lived in a non-remote area and non-traditionally oriented lifestyle. Nor did they use the discourse of racial fractions or skin colour, as the judges had in Condren's appeal. Indeed the police commissioner's directive specifically eschewed such a consideration:

Whilst many Aborigines and Torres Strait Islanders would fall into the category of persons under disability, pigmentation of the skin or genealogical background should not be used as a basis for this assessment. Whilst all of the factors outlined above [including age and developmental disability] should be considered, particular attention should be given to the suspect person's educational standards, knowledge of the English language, or any gross cultural differences. (as cited by Fitzgerald P in $R v$ Aubrey 1995)

In taking account of the directive, Davies J found that Aubrey had 'no difficulty in speaking and understanding English'. This finding was made on the basis of reading transcripts of Aubrey's evidence in the trial court, and on the decision of the trial judge that his 'command of the English language in the record of [police] interview was good, and he gave some quite long descriptive answers to questions'. It is quite likely that, as with many other people in Cherbourg, Aubrey's variety of Aboriginal English was close to general Australian English in terms of grammar and vocabulary, and thus he might be considered by many to have a 'good command of the English language'. However, this would be difficult to assess from reading answers to questions on a courtroom transcript. And it is also quite likely that he used pragmatic features such as those outlined above, and presented in the Queensland lawyers' handbook Aboriginal English and the Law (Eades 1992), which was referred to in Fitzgerald P's dissenting judgment.

It is relevant to point out that Fitzgerald $\mathrm{P}$ also took account of social conditions in Cherbourg, saying that the appellant's 'all-too-common life experience had left him poorly educated, unemployed, angry, aggressive and sometimes violent, especially when intoxicated'. While this is consistent with some of the factors in the Fernando principles, it was not invoked in relation to sentencing in this case, but as part (but not all) of the context for the appellant's engagement with police, which impacted on the extent of his 'disability' in the police interview. 
The differing approaches in Aubrey's case highlight the complexity for judicial officers in understanding and assessing both the likelihood that a person may be using English in an Aboriginal way, and the fact that this may need to be considered, regardless of whether this person is living with the 'grave social difficulties' at the heart of the Fernando decision about Aboriginality and sentencing. And this same complexity is also faced by police officers in their decision about their interviews with Aboriginal suspects.

It is interesting to compare this development in the three Queensland Appeal Court judgments, from the 1987 Condren judgment on the one hand, to the 1993 Kina judgment and the dissenting 1995 Aubrey judgment on the other hand. It might perhaps be suggested that the reports of the Royal Commission into Aboriginal Deaths in Custody and the Queensland lawyers' handbook (Eades 1992) could have contributed to change in judicial thinking about Aboriginal identity, although a causal connection would be impossible to establish. However, the contrasting ways of conceptualising Aboriginality in these cases probably had more to do with the individual judicial officers than with any widespread development in judicial thinking about Aboriginality over that time, thus highlighting the significance of judicial discretion. Justice Fitzgerald, who was the President of the Appeal Court of Queensland during the 1993 and 1995 appeals, had been the barrister defending Condren in his 1987 appeal (in which he called sociolinguistic evidence about Aboriginal English).

\section{Trial Communication: Leading Questions and Jury Directions}

When we turn to communication with Aboriginal witnesses in court, we see a number of initiatives both from judicial officers and from state justice departments. Since the three Queensland appeal cases discussed above, several states have drawn from research on Aboriginal ways of communicating in English in their publications intended to provide guidance for judicial officers and court staff (e.g. CJC 1996; Fryer-Smith 2008; Judicial Commission of New South Wales 2009; Queensland Department of Justice 2000; Queensland Supreme Court 2005). The Queensland lawyers' handbook (Eades 1992) has been extensively relied on. Within the judiciary, Justice Dean Mildren, who has been a Northern Territory Supreme Court judge since 1991, brings his extensive experience and his attention to sociolinguistic research to his judgments (e.g. $R v$ Kenny Charlie 1995), publications (e.g. Mildren 1997, 1999) and keynote addresses at conferences (e.g. Mildren 2012). Mildren has taken a strong lead in dealing with communication issues for Aboriginal people in court in two important areas. Firstly, while leading questions are typically considered central to the testing of witnesses in cross-examination, Mildren points out that the trial judge has the power 'to disallow questions, or forms of questions, which are unfair' 
(Mildren 1997: 14; also CJC 1996: 52). ${ }^{10}$ Recognising the role of gratuitous concurrence in rendering some Aboriginal people too suggestible for the fair use of leading questions in cross-examination, Mildren disallows leading questions in such situations (Mildren 1999: 147).

Secondly, for many years Mildren has been giving directions to juries about Aboriginal ways of using English. In 1995, the Criminal Justice Commission in Queensland asked Mildren and me to prepare a pro forma set of directions to be given to juries in Queensland cases involving witnesses who are speakers of Aboriginal English (published in CJC 1996: pp. A9-11; see also Mildren 1997, 1999). ${ }^{11}$ These directions have also been published in Queensland Supreme Court's 2005 Equal Treatment Benchbook (Appendix B in Chapter 9) and discussed in the NSW and WA equivalents (Judicial Commission of New South Wales 2009 and Fryer-Smith 2008). These specific directions, sometimes referred to as 'Mildren directions' or 'Mildren-style directions', are 'designed to assist a jury assessing the evidence of Aboriginal witnesses and/or an Aboriginal accused's record of interview. This is achieved by drawing the jury's attention to the possibility that sociolinguistic features of an Aboriginal witness's evidence may lead to misunderstandings (Fryer-Smith 2008: 7.4.1). Mildren (1997: 14) points out that the directions 'would obviously have to be moulded to the circumstances of the case'. And an important feature of the pro forma directions is the explicit warning of variation in the ways that Aboriginal people use English, as well as the frequent use of modifying expressions such as 'many Aboriginal people', 'often', and 'may'. That is, the directions should be impossible to apply in a categorical manner, and jurors are explicitly reminded that it is their 'function to decide which evidence [they] accept, and which evidence [they] reject' (CJC 1996: A9). While Justice Mildren has been using jury directions in the Northern Territory Supreme Court for at least 15 years, they are also used in some Western Australian cases (see Fryer-Smith 2008: 7.9-7.10), but they are reportedly not used in Queensland (Lauchs 2010: 17).

While it might perhaps be expected that Mildren's experience in the Northern Territory could result in a remote-area focus in his understandings of Aboriginality, this is not the case. Speaking at a national conference of criminal lawyers in 2012, he said 'even [Aboriginal] people who live in the major cities and towns are often influenced by their social or cultural background - even if they speak English quite well, and even if English is their first language' (2012: 6).

10 Leading questions are typically considered central to the testing of witnesses in cross-examination. While they most commonly have the syntactic form of yes/no questions, they are not defined in grammatical terms, but in legal terms: as questions which suggest a particular answer, or assume the existence of a fact which is in dispute.

11 A version of the directions was modified by Helen Harper for speakers of Torres Strait Creole. 
But, how do judicial officers (and police officers) decide when to use Mildren directions? How do they decide if information about Aboriginal ways of using English is relevant to the case at hand? Similarly, when is it relevant for a court to take note of expert evidence about differences between Aboriginal English and standard Australian English? It would presumably not be relevant if the Aboriginal witnesses in a case were Marcia Langton and Warren Mundine. But when is it relevant for others from southern Australia? What factors should lawyers and judges consider when addressing this question ${ }^{12}$

In discussions and workshops with judicial officers and legal professionals, I respond to such questions in terms of the bicultural/bidialectal ability to switch between Aboriginal ways of communicating in English in some situations, and mainstream Anglo ways in other situations. Bicultural and/or bidialectal ability is demonstrated in public life by Aboriginal political leaders, legal professionals, judicial officers, educators, public servants, filmmakers, musicians and more. But how can judicial officers and police officers know whether someone has considerable, or sufficient, bicultural and/or bidialectal ability? While this is clearly not always straightforward, to frame an answer to this question in terms of whether or not a person is a 'tribal [person] withdrawn from the European way of living' (as in the judge's decision in Aubrey's trial, see above) is clearly inadequate. It would also be inadequate to answer this question in terms of fractional descent, or the extent of a person's experience with police officers, following some of the sentencing decisions mentioned above. And it would not be relevant to consider the relevance of the witness's Aboriginality in terms of whether or not he had suffered from violence and alcohol abuse (which are central issues in the Fernando sentencing principles, as explained in 'Grave Social Difficulties', above). In the lawyers' handbook published more than two decades ago, I addressed this issue in terms of the socialisation of the person in question, and the evidence suggested by their successful participation in education, employment and leisure with non-Aboriginal people (Eades 1992: 12). Anthropologists might debate the basis for Aboriginal people's identity, and sociolinguists might debate contexts for the strategic essentialist use of 'Aboriginal English' versus 'Aboriginal ways of speaking English' (see Eades 2013). But in courts in southern Australia where Aboriginal people regularly give evidence, much more fundamental applications of our research are required, as the following examples will illustrate.

12 Parallel questions are relevant in situations in police interviews and courtroom hearings for Aboriginaland any other-witnesses who speak English as a second language: how do judicial officers (and police officers) decide if the L2 speaker needs an interpreter? (see Cooke 2009). 


\section{Leading Questions and Jury Directions: Questions of Specific Relevance}

The question of the relevance of sociolinguistic research about Aboriginal ways of using English was the subject of considerable deliberation in the 2004 Stack appeal in the Supreme Court of Western Australia. The specific focus of this deliberation comprised the two areas discussed above in which Justice Mildren has provided judicial leadership in relation to Aboriginal people's communication issues in court. In Stack, the Aboriginal applicant appealed his conviction, on manslaughter and unlawful wounding charges, because of the trial judge's Mildren-style directions to the jury (both at the commencement and the end of the trial) and his decision to stop leading questions being asked in the cross-examination of one of the prosecution witnesses, an 18-year-old Perth Aboriginal man. Thus, the communication issues were not raised in relation to the defendant, but to one of the witnesses giving evidence in his prosecution. The appeal was successful (with a two-to-one majority) on the grounds that leading questions in cross-examination should not have been stopped, and that it was 'not possible to be satisfied that no substantial miscarriage of justice resulted from the trial judge's ruling' on leading questions. That is, the conviction was overturned because of the appeal court's decision that the defendant's lawyer had been prevented from a thorough cross-examination of one of the prosecution witnesses.

In relation to the relevance of the Mildren directions about sociolinguistic features such as gratuitous concurrence, the judges considered several biographical factors, namely the witness's area of residence, his education and the fact that he spoke no Aboriginal languages. For example, Steytler J said (Stack $v$ Western Australia 2004: 553) that the witness

$$
\begin{aligned}
& \text { was an Aboriginal man who lived with his father in a Perth suburb and that } \\
& \text { he studied art and photography at TAFE in Kwinana [a Perth suburb] ... } \\
& \text { Subsequent evidence established that he attended Kwinana Senior High School } \\
& \text { up to halfway through year 10, that he did well at school and that he did not } \\
& \text { speak any Aboriginal languages. There is nothing in any of this evidence which } \\
& \text { would indicate that any generalised phenomenon, such as that of gratuitous } \\
& \text { concurrence, or any other failure to give appropriately responsive answers, } \\
& \text { was applicable to him. }
\end{aligned}
$$

The dissenting judge (Murray J) drew on similar biographical details of the witness, also highlighting the fact that the witness 'spoke no Aboriginal languages' (p. 535). While the factors of area of residence, education to midway through Year 10, followed by a TAFE course, and not speaking an Aboriginal language may often correlate with considerable ability to use English in a mainstream Australian way, this correlation is not a necessary one. That speaking 'no Aboriginal languages' was a criterion for all three appeal judges highlights 
the way that judicial officers (like many lawyers) still tend to look to clear markers of traditionally oriented practice to evaluate the relevance of a person's Aboriginality. However, sociolinguistic research on Aboriginal ways of using English, which are at the heart of the Mildren directions, do not appeal to use of an Aboriginal language to help provide guidance on a person's likely bicultural communication ability. ${ }^{13}$

Murray $\mathrm{J}$ also observed that 'there was no evidence that [the witness] lived a lifestyle different from any young person within the socioeconomic group of which his family and relatives appeared to be members' (p. 535). However, it should be noted that this apparent similarity of lifestyle with non-Aboriginal people could well mask subtle distinctively Aboriginal features of communicative practice, which still characterise Aboriginal family interactions in southern towns and cities, including Perth (see Malcolm et al. 2002).

In their careful consideration of the relevance of Aboriginal ways of using English to the witness in question, the appeal judges discussed not just the witness's biographical information, but they also gave evaluations of the witness's actual communication while giving evidence during the trial. Murray J commented that from his reading of the transcript of trial evidence, the witness 'appears to speak ordinary English and to display no signs of difficulty in expressing himself'. However, focusing on whether an Aboriginal speaker of English appears to have problems in expressing themselves, could well miss the subtle communication differences that arise from Aboriginal use of gratuitous concurrence, or silence, or different ways of giving specific information (see Eades 1992). Using English in an Aboriginal way may not sound like difficulty in communication, and indeed it may not comprise difficulty in communication. But it can contribute to miscommunication, where interlocutors are unaware of differences in the use and interpretation of English. While all three judges indicated general acceptance of the idea of gratuitous concurrence, two of them cited passages from the cross-examination which seemed to show the witness in question was able to disagree, sometimes 'vigorously', with propositions put to him.

But there was a difference between the two majority judges (Steytler $\mathrm{J}$ and Templeman J) and the third, dissenting judge (Murray J) which pointed to Murray J's recognition that reading a transcript of interaction is not the same as listening to it (see Eades 1996b, 2008). Murray J found that the trial judge's decision to stop leading questions and to give jury directions was made on the basis of information not accessible to the appeal court, which had 'not had the benefit of seeing and hearing [the witness] give evidence' (p. 535). Thus, his

13 Further, it is unlikely that many judicial officers in criminal jurisdictions would be aware of the complex relationships between self-reports about whether a person speaks an Aboriginal language, and actual linguistic and sociolinguistic practice (see McConvell and Thieberger 2001: 22-3). 
acceptance of the trial judge's decision concerning Aboriginal ways of using English was based on the fact that the trial judge's 'view of the way in which the witness was handling the process of questioning and giving evidence depended, not only upon the nature of his responses but upon the demeanour of the witness while giving evidence'.

The Stack case provides evidence of four judges addressing communication issues for Aboriginal speakers of English, and navigating the tricky question which we could express in terms of deciding the relevance of these issues for a particular witness, who may or may not have been socialised with these norms of language use, and who may or may not have bicultural communication abilities.

\section{A Problem-Centred Approach to Aboriginal Ways of Using English}

In contrast, these communication issues appear to have been dismissed with little consideration, and seemingly little understanding, in a NSW trial less than two years later. $R v$ Hart 2006 was the Supreme Court trial of a (non-Aboriginal) man for the murder of one of three local Aboriginal children in the small town of Bowraville. ${ }^{14}$ The prosecution was intending to call 50 Aboriginal witnesses from that town or with links to that community, where Aboriginal people make up 13 per cent of the population, and where Aboriginal ways of interacting, including ways of using English, are strong.

The investigating police officer had commissioned me to write a sociolinguistic report on communication issues which might have caused difficulties for the Aboriginal witnesses in communicating with police over the early years of the investigation, and which might also make it difficult for them to tell the court what they had seen and what they knew that was relevant to this case, and for their evidence to be understood. In this report I wrote about several ways in which Aboriginal use of English differs from mainstream Anglo use, such as gratuitous concurrence and the use and interpretation of silence, discussed above. This report included a recommendation about directions to the jury similar to those prepared for the Queensland CJC (1996) report, also discussed above.

Before the jury came into court, there was a brief courtroom discussion between lawyers and judge about the substance of the sociolinguistic report. The defence barrister said that he 'did not dispute the general thrust of Dr Eades' observations', saying that 'many people from the background of a large number of witnesses in this case do have the sorts of communication

14 This case is an important one for Aboriginal people's participation in the criminal justice system for many reasons, as exposed by a parliamentary inquiry (NSWPLC 2014); see also Knox (2010) and ABC (2011). 
eccentricities, to put it neutrally, as suggested by Dr Eades'. The fact that a lawyer can refer to sociolinguistic features described in an expert report in terms of 'communication eccentricities', and can attribute 'neutrality' to such a derogatory reference to linguistic features, shows just how little recognition and understanding there is among some members of the legal profession about cultural and dialectal differences in ways of using English. Further, this lawyer's erasure of Aboriginal identity with the euphemistic reference to 'people from the background of a large number of witnesses in this case' was consistent with the wider complaints from the Bowraville Aboriginal community that they were ignored by the criminal justice process (NSWPLC 2014; ABC 2011).

Having expressed lack of disagreement with the content of the sociolinguistic report, the defence barrister then argued against the use of such jury directions as recommended in my report, saying that it 'will introduce into an evaluation of [the Aboriginal] witnesses, an assessment of them, a whole range of assumptions which may or may not be appropriate'. This is despite the qualifications and caveats made explicit in the recommended directions, discussed above.

Interestingly, the prosecution (Crown) barrister had the opportunity to argue in favour of the relevance of the sociolinguistic report when he formally tendered (submitted) it to the court, but he did not do so, and he did not disagree with the defence argument about it. ${ }^{15}$ Nor did he take up the report's recommendation about directions to the jury.

This short general discussion between defence counsel, prosecuting counsel and judge, before the jury came into court, resulted in agreement not to present anything specific to the jury about Aboriginal use of English. However, seemingly prompted by this discussion, the judge (Hulme J) made the following general comment to the jury:

I understand that some of the witnesses are going to be Aboriginal and some people, particularly where their first language is not English, have some problems in terms of understanding or expressing themselves. Whether that is going to occur in this case, I have not got the foggiest idea. When it does, I will deal with it as I think appropriate, but you, in considering what you think of a witness, also bear in mind their apparent level of education or any other attributes. (from official trial transcript $R v$ Hart 2006)

Unlike the Stack appeal, in this case there was no discussion about the applicability of sociolinguistic differences to any particular witness. Thus, there was no assessment of Aboriginality. While the judge's stance is not overtly

15 An experienced lawyer has pointed out that the issue is complicated by legal complexities regarding the admissibility of expert evidence about language use and understanding. An examination of these complexities, while beyond the scope of this chapter, would in my view be valuable in providing further impetus for the recognition of the role of jury directions in many cases involving Aboriginal witnesses. 
demeaning or deficit-based, his comments are arguably more disturbing than the defence counsel's comment, revealing several problems which appear to prevent the understanding of Aboriginal identity, culture and social practice and its relevance to cases such as this.

Ignoring the two-way nature of communication, the judge's comment implies that the possibility of jurors misunderstanding Aboriginal witnesses occurs only to the extent that Aboriginal people might have problems of communication. It gives no indication of the much more common cause of intercultural miscommunication between Aboriginal and non-Aboriginal people, namely where there is no recognition of different ways of using English, for example that silence is used and interpreted differently, and that there are differences in the use of 'yes' answers to questions. Thus, this comment to the jury effectively invites jurors to base their evaluation of witnesses on ignorance, stereotypes, or even misunderstanding of Aboriginal communication, as it was made in the absence of any specific information about this topic. This is somewhat ironic, given the defence barrister's concerns about jurors bringing into their evaluation of Aboriginal witnesses 'a whole range of assumptions which may or may not be appropriate'. These comments by the judge to the jury also reveal apparent ignorance of the nature of the cultural and dialectal differences discussed in the expert report. It also revealed ignorance of the fact that Aboriginal people in Bowraville specifically, as throughout the state of NSW generally, are not second-language speakers of English.

\section{Conclusion}

Perhaps the judge's focus in the Hart case on Aboriginal problems in communication should not be surprising when we consider that so much judicial energy has focused on Aboriginal sentencing, in which individual histories of troubled Aboriginal people figure so prominently. Further, the leading judicial authority on the relevance of Aboriginality to sentencing in southern Australia - the 1992 Fernando judgment - highlights problems common to the experience of many Aboriginal people which can add significant weight to mitigating factors concerning the nature of the offender and the effect of the penalty (for example, reasons to weigh in the consideration of a prison term). Foremost among these mitigating factors are the 'grave social difficulties' including endemic alcohol problems referred to above.

But this chapter has argued that understanding Aboriginality is relevant not only to sentencing, but that it is also crucial to the way that Aboriginal witnesses are heard and how their stories are evaluated. In considering the relevance of Aboriginality to issues of communication, sentencing is not the goal, but rather 
a fair hearing of witnesses' stories, in interviews with lawyers and police officers, and in courtroom questioning. Thus, it is not people's individual problems stemming from alcohol abuse and violence which are at issue, but their linguistic socialisation and sociolinguistic experiences and abilities, as well as differences in ways of using language. It is true that many Aboriginal people who have suffered greatly in the colonisation and decolonisation process (and who thus would presumably meet the Fernando test) have, as a result, had limited opportunities to develop bicultural communication abilities. Thus, for example, many have not been successful participants in mainstream education and employment, two of the major social contexts where socialisation in the norms and practices of mainstream use of English occur. But there is not necessarily a neat overlap here between factors relevant to the application of the Fernando principles and those which call for the use of Mildren directions for the jury for example. Further, issues of alcohol abuse and violence, which often figure prominently in Aboriginal sentencing cases, are irrelevant to the sociolinguistic issues involved in Aboriginal ways of using English, and connected questions of intercultural communication. For example, there are many teetotaller speakers of Aboriginal English in rural and urban regions of southern Australia (as in other regions), and in order for them to communicate in court and in other legal contexts, it is issues of socialisation and language variety usage which need to be considered.

Thus, in cases where communication rather than sentencing is at issue, knowledge of the Fernando principles can provide a framework - whether consciously or unconsciously - for thinking about Aboriginality in terms of problems. Such an approach runs the risk of erasing Aboriginal identity, ignoring the two-way process of communication, and obscuring cultural and dialectal differences in ways of speaking English. The central premise of Ian Keen's (1988) book - that there are distinctive Aboriginal ways of life (or social practice) in southern Australia-remains just as relevant more than a quarter of a century after the initial publication of the book. Focusing on social practices involved in the Aboriginal use of English, we now have a clearer picture of how and why this is crucial in the criminal justice system. As we have seen in the discussion of Hart, effective intercultural communication and fair interpretation of the character and credibility of witnesses and their evidence requires abandoning a deficit view of Aboriginal identity and social practice, and developing understandings of culturally different ways of using the same language.

\section{Cases Cited}

Bugmy v R. 2013. Unreported, High Court of Australia 37, 2 October.

Neal v R. 1982. Commonwealth Law Reports 149, 305-26 (High Court). 
$R \quad v$ Anunga. 1976. Australian Law Reports 11, 412-7 (Northern Territory Supreme Court).

$R v$ Aubrey. 1995. Unreported, Queensland Court of Appeal, 28 April.

$R v$ Butler. 1991. Federal Law Reports 102, 341-9 (Northern Territory Supreme Court).

$R v$ Ceissman. 2001. Unreported, New South Wales Court of Criminal Appeal 73.

$R v$ Condren. 1987. Australian Criminal Reports 28, 261-99 (Queensland Court of Criminal Appeal).

$R v$ Fernando. 1992. Australian Criminal Reports 76, 58-65 (New South Wales Supreme Court).

$R v$ Hart. 2006. Unreported, New South Wales Supreme Court 1501, 7 July.

$R v$ Helmhout. 2001. Australian Criminal Reports 125, 257-67 (New South Wales Court of Criminal Appeal).

$R \quad v$ Kenny Charlie. 1995. Unreported, Northern Territory Supreme Court. 28 September.

$R v$ Kina. 1993. Unreported, Queensland Court of Appeal, 29 November.

$R v$ Newman, $R v$ Simpson. 2004. Australian Criminal Reports 145, 361-89 (New South Wales Court of Criminal Appeal).

Stack v Western Australia. 2004. Western Australian Reports 29, 526-65 (Western Australian Court of Criminal Appeal).

Waters $v$ Public Transport Corporation. 1991. Commonwealth Law Reports 173, 349-416.

\section{References}

ABC (Australian Broadcasting Commission). 2011. Bowraville: Unfinished Business. Four Corners [television documentary], 4 April 2011.

Aikman, A. 2012. Voices of authenticity. The Australian, 15 November, p. 13.

Anthony, T. 2010. Sentencing indigenous offenders. Indigenous Justice Clearinghouse Brief 7.

CJC (Criminal Justice Commission). 1996. Aboriginal Witnesses in Queensland's Criminal Courts. Brisbane: Criminal Justice Commission. 
Cooke, M. 2009. Anglo/Aboriginal communication in the criminal justice process: a collective responsibility. Journal of Judicial Administration 19: $26-35$.

Curthoys, A. 2002. Freedom Ride: A Freedom Rider Remembers. Sydney: Allen and Unwin.

Douglas, H. 1998. The cultural specificity of evidence: the current scope and relevance of the Anunga guidelines. UNSW Law Journal 21(1): 27-54.

Eades, D. 1992. Aboriginal English and the Law: Communicating with Aboriginal English Speaking Clients: A Handbook for Legal Practitioners. Brisbane: Queensland Law Society.

Eades, D. 1993. The case for Condren: Aboriginal English, pragmatics and the law. Journal of Pragmatics 20(2): 141-62.

Eades, D. 1994. A case of communicative clash: Aboriginal English and the legal system. In J. Gibbons (ed.), Language and the Law, pp. 234-64. London: Longman.

Eades, D. 1996a. Legal recognition of cultural differences in communication: the case of Robyn Kina. Language and Communication 16(3): 215-27.

Eades, D. 1996b. Verbatim courtroom transcripts and discourse analysis. In H. Kniffka (ed.), Recent Developments in Forensic Linguistics, pp. 241-54. Frankfurt: Peter Lang.

Eades, D. 1997. The acceptance of linguistic evidence about indigenous Australians. Australian Aboriginal Studies 1997 (1): 15-27.

Eades, D. 2003. 'I don't think the lawyers were communicating with me': misunderstanding cultural differences in communicative style. Emory Law Journal 52: 1109-34.

Eades, D. 2008. Telling and retelling your story in court: questions, assumptions, and intercultural implications. Current Issues in Criminal Justice 20(2): 209-30.

Eades, D. 2013. Aboriginal Ways of Using English. Canberra: Aboriginal Studies Press.

Edney, R. 2006. The retreat from Fernando and the erasure of Indigenous identity in sentencing. Indigenous Law Bulletin 6(17): 8-11. 
Family Court of Australia. n.d. Finding out about judgments. Accessed online 19 March 2013: www.familycourt.gov.au/wps/wcm/connect/FCOA/home/ judgments/about_judgments/.

Findlay, M., S. Odgers and S. Yeo. 2005. Australian Criminal Justice. Third edition. (First edition 1994). Oxford: Oxford University Press.

Flynn, M. 2005. Not 'Aboriginal enough' for particular consideration when sentencing? Indigenous Law Bulletin 6(9): 15-8.

Fryer-Smith, S. 2008. Aboriginal Cultural Awareness Benchbook for Western Australian Courts. Second edition. Perth: Australian Institute of Judicial Administration.

Johnston, E. 1991. Royal Commission into Aboriginal Deaths in Custody National Report: Overview and Recommendations. Canberra: Australian Government Publishing Service.

Judicial Commission of New South Wales. 2009. Equality before the Law Benchbook. Sydney: Judicial Commission of New South Wales.

Judicial Commission of New South Wales. 2013. Relevance of deprived background of an Aboriginal offender: Bugmy $v$ The Queen [2013] HCA 37; Munda $v$ Western Australia [2013] HCA 38. Special Bulletin 4, October 2013.

Judicial Commission of New South Wales. n.d. Ngara Yura Program. Accessed online 4 March 2013: www.judcom.nsw.gov.au/Ngara-Yura.

Keen, I. 1988. Being Black: Aboriginal Cultures in Settled Australia. Canberra: Aboriginal Studies Press.

Knox, M. 2010. The mission. The Monthly October: 40-7.

Langton, M. 1981. Urbanizing Aborigines: the social scientists' great deception. Social Alternatives 2(2): 16-22.

Lauchs, M. 2010. Rights versus reality: the difficulty of providing 'access to English' in Queensland courts. Report published by Faculty of Law, Queensland University of Technology, Brisbane.

Malcolm, I.G., P. Königsberg, G. Collard, A. Hill, E. Grote, F. Sharifian, A. Kickett and E. Sahanna. 2002. Umob Deadly: Recognized and Unrecognized Literacy Skills of Aboriginal Youth. Mt Lawley, WA: Edith Cowan University. 
McConvell, P. and N. Thieberger. 2001. State of Indigenous Languages in Australia-2001. Australia State of the Environment Second Technical Paper Series (Natural and Cultural Heritage). Canberra: Department of the Environment and Heritage.

Mildren, D. 1997. Redressing the imbalance against Aboriginals in the criminal justice system. Criminal Law Journal 21(1): 7-22.

Mildren, D. 1999. Redressing the imbalance: Aboriginal people in the criminal justice system. Forensic Linguistics 6(1): 137-60.

Mildren, D. 2012. Indigenous Australians and the criminal justice system. Paper presented to the Uluru Criminal Lawyers Conference, August.

NSWPLC (New South Wales Parliament Legislative Council Standing Committee on Law and Justice). 2014. The Family Response to the Murders in Bowraville (Report 55). Sydney: New South Wales Parliament Legislative Council.

Nicholson, J. 2012. Sentencing Aboriginal offenders: A judge's perspective. Paper presented to the Uluru Criminal Lawyers Conference, August.

Queensland Department of Justice. 2000. Aboriginal English in the Courts: A Handbook. Brisbane: Department of Justice.

Queensland Supreme Court. 2005. Equal Treatment Benchbook. Brisbane: Supreme Court of Queensland Library.

Rowley, C.D. 1971. Outcasts in White Australia. Canberra: Australian National University Press.

Rowse, T. 2012. Rethinking Social Justice: From 'Peoples' to 'Populations'. Canberra: Aboriginal Studies Press.

SCRGSP (Steering Committee for the Review of Government Service Provision). 2014. Overcoming Indigenous Disadvantage: Key Indicators 2014. Canberra: Productivity Commission.

Skyring, F. 2011. Justice: A History of the Aboriginal Legal Service of Western Australia. Perth: UWA Publishing.

Williams, M.S. 2013. High Court to give 'full weight' to Indigenous disadvantage. The Conversation. Accessed online 22 January 2014 at: theconversation.com/ high-court-to-give-full-weight-to-indigenous-disadvantage-18880.

Yehia, D. 2012. Admissibility of admissions: Aboriginal and Torres Strait Islander suspects. Paper presented to the Uluru Criminal Lawyers Conference, August. 
This text is taken from Strings of Connectedness: Essays in Honour of Ian Keen, edited by Peter Toner, published 2015 by ANU Press, The Australian National University, Canberra, Australia. 